Ege Tıp Dergisi / Ege Journal of Medicine 2018;57(4):185-190

\title{
Glukoz metabolizma bozukluklarında subklinik aterosklerozun değerlendirilmesi
}

Assessment of subclinical atherosclerosis in glucose metabolism disorders

\author{
Elçin Aydın ${ }^{1} \quad$ Cihan Altın $^{2} \quad$ Sinan Emre $^{3}$ Muhteşem Ağıldere ${ }^{4} \quad$ Mustafa Agah Tekindal $^{5}$ \\ ${ }^{1}$ Başkent Üniversitesi Tıp Fakültesi, Radyoloji Anabilim Dalı, İzmir, Türkiye \\ ${ }^{2}$ Başkent Üniversitesi Tıp Fakültesi, Kardiyoloji Anabilim Dalı, İzmir, Türkiye \\ ${ }^{3}$ Başkent Üniversitesi Tıp Fakültesi, Göz Hastalıkları Anabilim Dalı, İzmir, Türkiye \\ ${ }^{4}$ Başkent Üniversitesi Tıp Fakültesi, Radyoloji Anabilim Dalı, Ankara, Türkiye \\ ${ }^{5}$ Selçuk Üniversitesi Veteriner Fakültesi Biyoistatistik Anabilim Dalı, Konya, Türkiye
}

\section{Öz}

Amaç: Diyabet $(D)$ ve prediyabette $(P D)$ vasküler yapıların ve gözün etkilenmesi bilinen bir komplikasyondur. Çalışmamızda PD ve D hastalarında damarsal yapılardaki değişiklikleri karotis intima-media kalınlığı (KIMK) ve epikardiyal yağ kalınlığı (EYK) ölçerek ateroskleroz gelişim riski açısından, gözde ise optik koherens tomografi anjiografi (OKTA) kullanarak retinal ve koroidal vasküler değişiklikler açısından sunmayı amaçladık.

Gereç ve Yöntem: Çalışmamızda Mayıs 2017- Haziran 2017 tarih aralığındaki laboratuar verilerine göre prediyabet ve diyabet tanısı alan hastalarda KIMK, EYK ölçümü ile ateroskleroz riski ve OKTA tekniği ile retinal ve koroidal vasküler değişiklikler; 19 prediyabetik, 12 diyabetik olguda, hastaların yaşı ve cinsiyeti benzer olan 31 normal kan şekeri seviyesine sahip bilinen koroner arter hastalığı olmayan kontrol (K) grubu ile karşılaştırılarak kaydedildi.

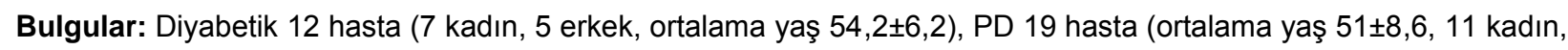

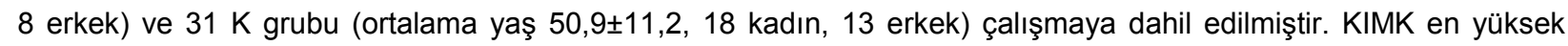
diyabetli hastalarda, daha sonra PD ve en az miktarda kontrol hastalarında bulunmuştur. EYK'de gruplar arası farklılık ayırtedilmedi. OKTA verilerine göre en sık bulgu non-perfüzyon, FAZ (foveal avaskuler zon) erozyonu ve venöz göllenme olup en fazla diyabetli hastalarda, sonra PD ve en az K grubunda izlenmiştir.

Sonuç: Subklinik aterosklerozun belirteçleri olan KIMK ve EFT'ye ek olarak retinal vasküler hastalıkların OKTA ile girişimsel olmayan yöntemlerle değerlendirmesinde glukoz metabolizması bozukluğu olan hastaların risk değerlendirilmesinde katkı sağlayacaktır.

Anahtar Sözcükler: Prediyabet, diyabet, ateroskleroz, karotis intima media kalınlığı, epikardiyal yağ kalınlığı, optik koherens tomografi anjiografi.

\section{Abstract}

Aim: It is a well-known complication that diabetes (DM) and prediabetes (PD) affectsvascular structures and eye. In our study we aim to find out the atherosclerotic changes in patients with $P D$ and DM by using carotis intima-media thickness (CIMT), epicardial fat thickness (EFT) and rusing optical coherence tomography angiography (OCTA).

Materials and Methods: Between May 2017- June 2017 consecutive 19 patients with PD and 12 patients with D were enrolled into the study. They compared with age sex matched control (C) group consisted of 31 individuals who have normal blood glucose levels. Patients with coronary artery disease was excluded. Measurements of CIMT, EFT and retinal and choroidal vascular changes by using OCTA technique obtained from our study group were recorded and compared with each other.

\footnotetext{
Yazışma Adresi: Elçin Aydın

Başkent Üniversitesi Tıp Fakültesi, Radyoloji Anabilim Dalı , İzmir, Türkiye

Makalenin Geliş Tarihi: 13.08.2017 Kabul Tarihi: 07.09.2017
} 


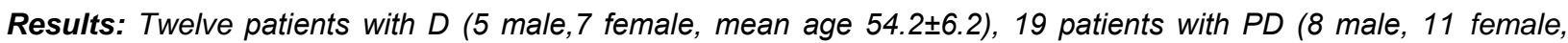

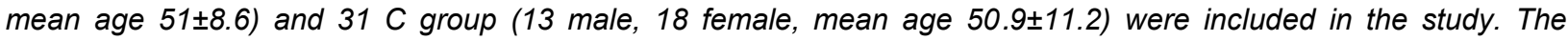
highest value of CIMT was found in patients wih $D$ following by patients with $P D$ and control group had the lowest values. There was no difference between groups in EFT. The most common findings in OCTA were non-perfussion, $F A Z$ (foveal avascular zone) erosion and venous pooling. Similarly these findings were more frequent in patient DM following by patients with $P D$.

Conclusion: Non invasive measurement of CIMT, EFT and retinal vascular changes detected by OCTA are useful and feasible tools for the assessment of subclinical atheroscleoris in patients with glucose metabolism disorders.

Keywords: Prediabetes, diabetes mellitus, atherosclerosis, carotis intima media thickness, epicardial fat thickness, optical coherence tomography angiography.

\section{Giriş}

Diyabet ve prediyabette vasküler yapıların etkilenmesi bilinen bir komplikasyondur. Subklinik ateroskleroz gerek kardiyovasküler hastalıklar gerekse serebrovasküler hastalıkların semptom vermesinden yıllar öncesinde gelişmeye başlar (1). Karotis intima-media kalınlığı (KIMK) ve epikardiyal yağ kalınlığı (EYK) ölçümü erken aterosklerozu gösteren belirteçlerdir (2-4).

Optik koherens tomografi anjiografi (OKTA) ise yeni geliştirilen non-invaziv, yüksek rezolusyonlu retinal kan damarlarına yönelik bir incelemedir. Prediyabet ve diyabet hastalarında göz en çok etkilenen organlardan birisidir. OKTA tekniği ile retinal ve koroidal dolaşım noninvaziv biçimde saptanabilmektedir (5-7).

Biz çalışmamızda prediyabet ve diyabet hastalarında damarsal yapılardaki aterosklerotik değişiklikleri KIMK ve EYK ölçerek, gözde ise OKTA kullanarak retinal ve koroidal vasküler değişiklikleri araştırmayı amaçladık.

\section{Gereç ve Yöntem}

Çalışmamıza hastanemizde Mayıs 2017-Haziran 2017 tarih aralığında prediyabet ve diyabet tanısı alan 19 prediyabetik, 12 diyabetik olgu ve bu hastalara cinsiyet yaş açısından benzer 31 normal kan şekeri seviyesine sahip hastalar dahil edildi. Koroner arter hastalığı ve eş değeri vasküler hastalığı olan hastalar dışlandı. Çalışmaya alınan tüm bireylere KIMK, EYK ölçümü yapıldı ve OKTA tekniği ile retinanın superfisiyal ve derin vasküler pleksusları ve koroidal vasküler pleksustaki değişiklikler değerlendirildi. Kaydedilen veriler kontrol grubu ile karşılaştırıldı.

EYK ölçümü transtorasik ekokardiyografi (TTE); Vivid S5e (GE Healthcare, Horten, Norveç) 3S-RS band aralığında; ile sağ ventrikül serbest duvar komşuluğundan, parasternal uzun ve kısa akstan yapılmıştır. Ölçümler sağ ventrikül duvarına dik olarak, diyastol sonunda gerçekleştirildi (Şekil-1).

Her olgunun karotis intima media kalınlığı, B-mod ultrasonografi cihazı ile (Arietta-70, Tokyo, Japonya) 9 Mhz prob ile, her iki ana karotis arterin yaklașı 1-1.5 cm'lik distal bölümünden, yalnızca posterior duvardan, dörder kez ölçüldü, ölçülen değerlerin ortalaması alınıp kaydedildi (Şekil-2).

OKTA bulguları, (Optovue, Fremont, Amerika Birleşik Devletleri), her bir göz için yüzeyel retinal kapiller pleksusu, derin retinal kapiller pleksus ve koroidokapiller yatak için mikroanevrizma, retinal neovaskülarizasyon, vasküler lup, non-perfüzyon, FAZ (foveal avaskuler zon) erozyonu, venöz göllenme, multipl kapiller yataklar varlığı açısından değerlendirildi (Şekil-3).

Elde edilen veriler, istatistik paket programı SPPS 20 (IBM Corp. Released 2011. IBM SPSS Statistics for Windows, Version 20.0. Armonk, NY: IBM Corp.) kullanılarak analiz edildi. Çalışmada kategorik ve sürekli değişkenler için tanımlayıcı istatistikler (ortalama, standart sapma, ortanca değer, minimum, maksimum, sayı ve yüzdelik dilim) verildi. Ayrıca parametrik testlerin ön şartlarından varyansların homojenliği Levene testi ile kontrol edildi. Normallik varsayımına ise Shapiro-Wilk testi ile bakıldı. İki grup arasındaki farklılıklar değerlendirilmek istendiğinde parametrik test ön şartlarını sağladığı durumda Student's $t$ test, sağlamadığında ise Mann Whitney- $U$ test kullanıldı. Üç ve daha fazla grup karşılaştırması için Tek Yönlü Varyans Analizi ve çoklu karşılaştırma testlerinden Tukey HSD testi ile sağlanmadığında ise Kruskal Wallis ve çoklu karşılaştırma testlerinden Bonferroni-Dunn testi kullanıldı. Sürekli iki değişken arasındaki ilişki Pearson Korelasyon Katsayısı ile parametrik test ön şartlarını sağlamadığı durumda ise Spearman Korelasyon Katsayısı ile değerlendirildi. Kategorik değişkenler arasındaki ilişkiler Fisher's Exact Test ve Ki Kare testi ile analiz edildi. Beklenen frekansların \%20'den küçük olduğu durumlarda bu frekansların analize dahil edilmesi için Monte Carlo Simulasyon Yöntemi ile değerlendirme yapıldı. $p<0,05$ ve $p<0,01$ düzeyi istatistik olarak anlamlı kabul edildi.

\section{Bulgular}

Laboratuvar verilerine göre diyabet tanısı konan 12 hasta (ortalama yaş $54,2 \pm 6,2 ; 7$ kadın, 5 erkek), prediyabetik 19 hasta (ortalama yaş $51 \pm 8,6$; 11 kadın, 8 erkek) ve kan şekeri normal sınırlarda bulunmuş 31 kontrol grubu (ortalama yaş $50,9 \pm 11,2$; 18 kadın, 13 erkek) çalışmaya dahil edildi. 
OKTA verilerine göre yüzeyel retinal pleksusda en sık bulgu non-perfüzyon ve venöz göllenme olup en fazla diyabetli hastalarda, sonra prediyabet ve en az kontrol grubunda izlendi. Derin retinal kapillerlerde en sık bulgu nonperfüzyon ve FAZ erozyonu olarak gözlenmiştir, en sık diyabetik hastalarda ve prediyabetlilerde saptandı.
Koriokapiller düzeyde nonperfüzyon ve $F A Z$ erozyonu en sık görülen bulgu olup diyabetlilerde en fazla bulunmuştur (Tablo-1). KIMK en yüksek diyabetli hastalarda, daha sonra prediyabette ve en az miktarda kontrol hastalarında bulunmuştur (Tablo-2). EYK'de gruplar arasında anlamlı fark bulunmamaktadır (Tablo-2).

Tablo-1. OKTA Bulgularının Hastalara Göre Dağılımı.

\begin{tabular}{|c|c|c|c|c|c|c|c|}
\hline & \multicolumn{3}{|c|}{ Grup } & \multirow{2}{*}{ Toplam } & \multirow{2}{*}{$p$} \\
\hline & & & Kontrol & Prediyabet & Diyabet & & \\
\hline \multirow{6}{*}{ SRAL } & \multirow{2}{*}{ SRAL2 } & $n$ & 0 & 2 & 1 & 3 & \multirow{7}{*}{$0,02^{\star \varepsilon}$} \\
\hline & & $\%$ & 0,0 & 66,7 & 33,3 & & \\
\hline & \multirow{2}{*}{ SRAL3 } & $\mathrm{n}$ & 1 & 2 & 3 & 6 & \\
\hline & & $\%$ & 16,7 & 33,3 & 50,0 & & \\
\hline & \multirow{2}{*}{ SRAL5 } & $\mathrm{n}$ & 1 & 1 & 4 & 6 & \\
\hline & & $\%$ & 16,7 & 16,7 & 66,7 & & \\
\hline \multicolumn{2}{|c|}{ Toplam } & $\mathrm{n}$ & 2 & 4 & 5 & 11 & \\
\hline \multirow{8}{*}{ SRAR } & \multirow{2}{*}{ SRAR1 } & $n$ & 0 & 0 & 1 & 1 & \multirow{9}{*}{$0,049^{\star £}$} \\
\hline & & $\%$ & 0,0 & 0,0 & 100,0 & & \\
\hline & \multirow{2}{*}{ SRAR2 } & $\mathrm{n}$ & 1 & 2 & 1 & 4 & \\
\hline & & $\%$ & 25,0 & 50,0 & 25,0 & & \\
\hline & \multirow{2}{*}{ SRAR3 } & $\mathrm{n}$ & 2 & 2 & 2 & 6 & \\
\hline & & $\%$ & 33,3 & 33,3 & 33,3 & & \\
\hline & \multirow{2}{*}{ SRAR5 } & $\mathrm{n}$ & 0 & 0 & 4 & 4 & \\
\hline & & $\%$ & 0,0 & 0,0 & 100,0 & & \\
\hline \multicolumn{2}{|c|}{ Toplam } & $\mathrm{n}$ & 3 & 4 & 5 & 12 & \\
\hline \multirow{8}{*}{ DRAL } & \multirow{2}{*}{ DRAL1 } & $n$ & 0 & 1 & 2 & 3 & \multirow{9}{*}{$0,001^{* \star \varepsilon}$} \\
\hline & & $\%$ & 0,0 & 33,3 & 66,7 & & \\
\hline & \multirow{2}{*}{ DRAL2 } & $\mathrm{n}$ & 0 & 0 & 1 & 1 & \\
\hline & & $\%$ & 0,0 & 0,0 & 100,0 & & \\
\hline & \multirow{2}{*}{ DRAL3 } & $\mathrm{n}$ & 1 & 3 & 3 & 7 & \\
\hline & & $\%$ & 14,3 & 42,9 & 42,9 & & \\
\hline & \multirow{2}{*}{ DRAL5 } & $\mathrm{n}$ & 4 & 9 & 9 & 22 & \\
\hline & & $\%$ & 18,2 & 40,9 & 40,9 & & \\
\hline & & $\mathrm{n}$ & 5 & 11 & 10 & 26 & \\
\hline & DRAR1 & $\mathrm{n}$ & 0 & 0 & 2 & 2 & \\
\hline & DחAחI & $\%$ & 0,0 & 0,0 & 100,0 & & \\
\hline DRAR & RRAR3 & $\mathrm{n}$ & 2 & 2 & 3 & 7 & \\
\hline 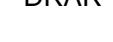 & & $\%$ & 28,6 & 28,6 & 42,9 & & $0,03^{\star £}$ \\
\hline & RRAR5 & $n$ & 3 & 5 & 7 & 15 & \\
\hline & DRARS & $\%$ & 20,0 & 33,3 & 46,7 & & \\
\hline & & $\mathrm{n}$ & 5 & 7 & 8 & 20 & \\
\hline & $\mathrm{KKL} 3$ & $\mathrm{n}$ & 7 & 8 & 6 & 21 & \\
\hline KKL & NALO & $\%$ & 33,3 & 38,1 & 28,6 & & \\
\hline $\mathrm{NAL}$ & $K K \mid 5$ & $n$ & 0 & 0 & 1 & 1 & $0,001^{* * \varepsilon}$ \\
\hline & KNLS & $\%$ & 0,0 & 0,0 & 100,0 & & \\
\hline & & $\mathrm{n}$ & 7 & 8 & 6 & 21 & \\
\hline & KKR3 & $\mathrm{n}$ & 5 & 7 & 5 & 17 & \\
\hline KKR & & $\%$ & 29,4 & 41,2 & 29,4 & & \\
\hline KRn & KKR5 & $\mathrm{n}$ & 0 & 0 & 1 & 1 & $0,001^{* \star \varepsilon}$ \\
\hline & КККБ & $\%$ & 0,0 & 0,0 & 100,0 & & \\
\hline & & $\mathrm{n}$ & 5 & 7 & 5 & 17 & \\
\hline $\begin{array}{l}\text { RAL: Sol } \\
\text { iağ derin re } \\
\text { ptik kohe } \\
\text { eovaskülar } \\
0<0,05 \\
0<0,01 \\
\text { Ki Kare tes }\end{array}$ & $\begin{array}{l}\text { rfisial retina } \\
\text { plexus, KK } \\
\text { tomograf } \\
\text { yon, } 5 \text {-faz e } \\
\text { lonte Carlo }\end{array}$ & $\begin{array}{l}\text { ple } \\
\text { rapi } \\
\text { rafi }\end{array}$ & $\begin{array}{l}\text { R: Sağ } \\
\text { sol, KK } \\
\text { bulgule } \\
\text { ame, 7-n }\end{array}$ & $\begin{array}{l}\text { rfisial retinal } \\
\text { riokapiller ple } \\
\text { 1-mikroanevr } \\
\text { I kapiller yata }\end{array}$ & $\begin{array}{l}\text { xus, DRA } \\
\text { s sağ. } \\
\text { na, 2-vas }\end{array}$ & $\begin{array}{l}\text { derin re } \\
\text { lup, } 3\end{array}$ & $\begin{array}{l}\text { lexus, DRA } \\
\text { erfüzyon, }\end{array}$ \\
\hline
\end{tabular}


Tablo-2. Karotis İntima Media Kalınlığı ve Epikardiyal Yağ Yastıkçığı.

\begin{tabular}{|c|c|c|c|c|}
\hline \multicolumn{5}{|c|}{ Grup } \\
\hline & Kontrol & Prediyabet & Diyabet & $\mathrm{p}$ \\
\hline KIMKL & $0,67 \pm 0,15^{\mathrm{ab} \pitchfork}$ & $0,75 \pm 0,21^{\text {b๘ }}$ & $0,86 \pm 0,16$ & $0,006^{* *^{2}}$ \\
\hline KIMKR & $0,7 \pm 0,17$ & $0,79 \pm 0,34$ & $0,85 \pm 0,2$ & $0,137^{z}$ \\
\hline EYK & $0,63 \pm 0,25$ & $0,72 \pm 0,2$ & $0,76 \pm 0,19$ & $0,201^{z}$ \\
\hline LA (cm) & $3,41 \pm 0,53$ & $3,58 \pm 0,5$ & $3,53 \pm 0,28$ & $0,446^{z}$ \\
\hline $\mathrm{RA}(\mathrm{cm})$ & $3,29 \pm 0,65$ & $3.3 \pm 0.41$ & $3,28 \pm 0,24$ & $0,991^{₹}$ \\
\hline $\begin{array}{l}\text { LVS } \\
\text { (cm) }\end{array}$ & $2,97 \pm 0,36$ & $3,13 \pm 0,38$ & $3,07 \pm 0,31$ & $0,309^{z}$ \\
\hline $\begin{array}{l}\text { LVD } \\
(\mathrm{cm})\end{array}$ & $4,6 \pm 0,39$ & $4,73 \pm 0,39$ & $4.73 \pm 0.24$ & $0,375^{z}$ \\
\hline IVS (cm) & $1,21 \pm 0,1$ & $1,2 \pm 0,12$ & $1,12 \pm 0,13$ & $0,051^{z}$ \\
\hline $\mathrm{PW}(\mathrm{cm})$ & $1,15 \pm 0,08$ & $1,15 \pm 0,09$ & $1,08 \pm 0,12$ & $0,067^{₹}$ \\
\hline $\mathrm{EF}(\%)$ & $57,9 \pm 4,26^{b \ell}$ & $58,05 \pm 3,54^{\mathrm{bl}}$ & $61,58 \pm 4,5$ & $0,059^{\Delta}$ \\
\hline
\end{tabular}

Gruplar arasında KIMK haricinde ejeksiyon fraksiyonu da dahil olmak üzere diğer ekokardiyolografi bulguları arasında fark yoktu.

KIMKL: Sol karotis intima-media kalınlığı, KIMKR: Sağ karotis intimamedia kalınlığı, EYK: Epikardiyal yağ kalınlığı, LA: Sol atrium, RA: Sağ atrium, LVS: Sol ventrikül siatol sonu çapı, LVD: Sol ventrikül diyasto sonu çapı, IVS: İnterventriküler septum, PW: Posterior wall, EF: Ejeksiyon fraksiyonu

${ }^{* *} \mathrm{p}<0,01$,

K: Kontrol, P: Prediyabet, D: Diyabet.

a: P'den farklı

b: D'den farkl

₹: Tek Yönlü Varyans Analizi

th: Tukey HSD testi

$\Delta$ : Kruskal Wallis Test

$\ell$ : Bonferroni-Dunn testi

\section{Tartışma}

İnsülin salgılanmasının bozulması veya insuline karşı direnç gelişmesi sonucunda glukoz metabolizması bozuklukları meydana gelmektedir. Hastaların bir kısmında Tip 2 diabetes mellitus (DM) gelişirken, bir kısmında da prediyabetik durumlar olduğu düşünülen bozulmuş açlık glukozu (BAG) ve bozulmuş glukoz toleransı (BGT) meydana gelmektedir. Çeşitli kılavuzlarda, prediyabetik durumlar olarak ele alınan BAG ve BGT; metabolik sendrom, Tip 2 DM ve kardiyovasküler hastalık gelişimi için bağımsız risk faktörleri olarak kabul görmektedir (1). American Diabetes Association (ADA) kriterlerine göre; açlık plazma glukozu $100 \mathrm{mg} / \mathrm{dL}$ ile $125 \mathrm{mg} / \mathrm{dL}$ arasında ölçülen hastalar BAG, oral glukoz tolerans testinde (OGTT) 2. saat plazma glukoz düzeyi $140-199 \mathrm{mg} / \mathrm{dL}$ ölçülen hastalar ise BGT olarak belirlenmiştir (8). Bu grup hastalarda klinik DM henüz ortaya çıkmamıştır ve çoğu günlük yaşamlarında öglisemiktir. $\mathrm{HbA} 1 \mathrm{c}$ değerleri genellikle normal seviyelerde olmasına rağmen HbA1c'den bağımsız artmış kardiyovasküler risk bulunmaktadır (9).

Çalışmamızda diyabetik ve prediyabetik hastalarda kontrol grubuna göre subklinik aterosklerozu gösteren KIMK'nın yüksek çıkması bu sonucu desteklemektedir.
KIMK; aterosklerotik damar hastalıklarının subklinik dönemde tanınması ve takibinde kullanılan, kolay ulaşılabilir, basit, ucuz, girişimsel olmayan ve objektif değerlendirme sağlayan bir yöntemdir (10-12). Yapılan klinik çalışmalarda KIMK'nın metabolik sendromlu hastalarda subklinik aterosklerozun önemli bir göstergesi olduğu bulunmuştur (13).

Koroner arter hastalığı, miyokard infaktüsü ve inme için bağımsız bir belirteç olan KIMK'ın önemi son kılavuzlarda vurgulanmış, KIMK>09 mm olmasının vasküler hasarın bir göstergesi olduğu kabul edilmiştir (13-15).

Epikardiyal yağ dokusu (EYD), epikardiyum üzerinde mezodermden köken alan bir yağ dokusudur. Koroner arterlerin üzerini saran EYD en fazla sağ ventrikül serbest duvarı çevresinde bulunmaktadır $(16,17)$. EYD visseral yağ dokusu ile koreledir ve metabolik sendrom risk faktörleri ile yakından ilişkilidir. Yapılan çalışmalarda EYD'nin genel toplam yağ dokusu miktarından ziyade visseral yağlanma ile ilişkisi olduğu kanıtlanmıştır (1619,20). Kardiyovasküler hastalık gelişiminin de genel toplam yağ dokusu miktarından çok visseral yağlanma ile ilişkili olduğu bilinmektedir (19-22). EYD yeni önerilen bir metabolik sendrom kriteri olup insülin rezistansı, hipertansiyon ve dislipidemi ile ilişkisi gösterilmiştir $(21,23)$. EYD, koroner arter hastalığı $(K A H)$ gelişimi için bağımsız bir risk faktörüdür (24). EYD vasküler, inflamatuar ve enerji metabolizması üzerinde etkili sitokin benzeri birçok biyoaktif moleküllerin kaynağıdır.

EYD'nin bazı biyoaktif molekülleri (interlökin-6, TNF-a) çok daha yüksek oranda ürettiği gösterilmiştir ve bu durumun da artmış inflamasyon, insulin rezistansı ve ateroskleroz ile ilişkili olduğu düşünülmektedir (25).

EYD ölçümü transtorasik ekokardiyografi (TTE), bilgisayarlı tomografi (BT) ve manyetik rezonans (MR) gibi birçok görüntüleme yöntemi ile yapılabilmektedir. İki boyutlu görüntü sağlaması ve akustik pencereye bağımlılık gibi çeşitli kısıtlamalara rağmen TTE, EYD ölçümü için altın standart kabul edilen MR ile iyi korelasyon gösteren, yeterli, tekrarlanabilir, basit ve ucuz bir görüntüleme metodudur $(19,26,27)$. EYD ölçümü genel olarak TTE ile sağ ventrikül serbest duvar komşuluğundan, parasternal uzun ve kısa akstan yapılmıştır. Yapılan çalışmalardan çıkan sonuca göre, ölçümlerin sağ ventrikül duvarına dik olarak, diyastol sonunda yapılması önerilmektedir $(19,28)$.

$\mathrm{KIMK} \geq 1 \mathrm{~mm}$ olan hastalarda vasküler hasarın başladığı kabul edilmekte ve tedavi rejimi ona göre düzenlenmektedir $(10,11)$. Çalışmamızda EYK ve KIMK değerleri en fazla diyabetik hastalarda ikinci sıklıkta prediyabetiklerde ve en az olarak kontrol grubunda izlenmektedir.

Diyabet tüm dünyada en önemli körlük nedenlerinden birisi olarak gösterilmektedir. Diyabet hastalığı uzun dönemde katarakt, glokom, görme keskinliğinde değişimler ve 
diyabetik retinopati gibi göz sağlığı sorunlarına neden olmaktadır. Glikoz metabolizma bozukluklarında retina ve koroid tabakasının değerlendirilmesine ilişkin çalışma daha önce yapılmamıştır. OKTA son yıllarda geliştirilen ve retina ve koroid tabakasının kontrast madde verilmeden gösterilmesini sağlayan bir tekniktir (29). Gerek diyabet gerekse glikoz metabolizma bozukluğu olan hastalarda retina ve koroid etkilenmesi OKTA ile non-invaziv şekilde gösterilebilecektir.

Diyabetik retinopati gelişmeden de glukoz metabolizma bozukluğu olan hastalarda erken dönemde retinal vasküler değişiklikler görülebilmektedir (5-7). OKTA'da superfisiyal retinal kapiller pleksus, derin retinal kapiller pleksus ve koriokapiller kapiller pleksus incelenmektedir. Diyabet ve prediyabet olgularında arterlerdeki başlıca değişiklikler; mikroanevrizma, vasküler lup, non-perfüzyon, neovaskülarizasyon, faz erozyon, venöz göllenme, multipl kapiller yataklar şeklindedir. Çalışmamızda beklenildiği üzere retinal vasküler yapılarda ve koriokapiller düzeyde değişiklikler diyabet ve prediyabetlilerde kontrol grubuna nazaran fazladır.

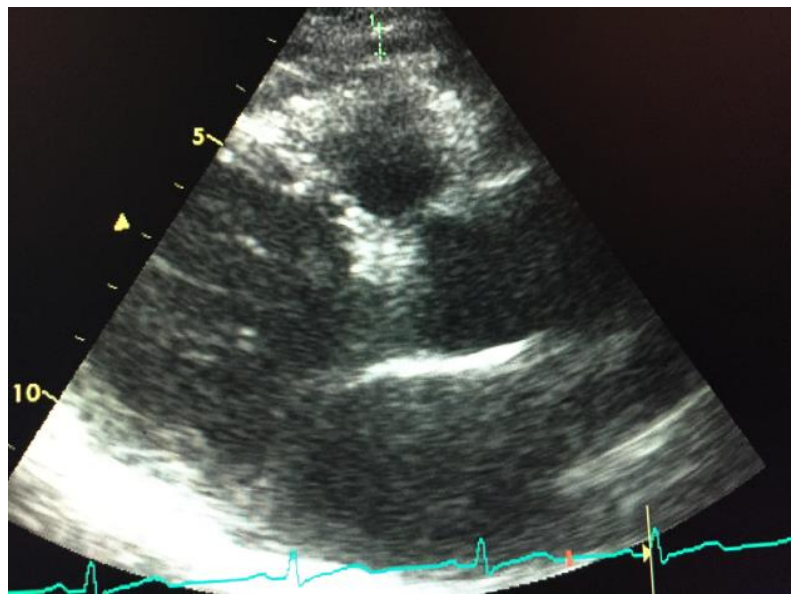

Şekil-1. Ekokardiyografide epikardiyal yağ yastıkçığı ölçümü.

\section{Sonuç}

Subklinik aterosklerozun belirteçleri olan KIMK ve EYK'na ek olarak retinal vasküler hastalıkların OKTA ile girişimsel olmayan yöntemlerle değerlendirmesi, glukoz metabolizması bozukluğu olan hastaların risk değerlendirilmesine katkı sağlayacaktır.

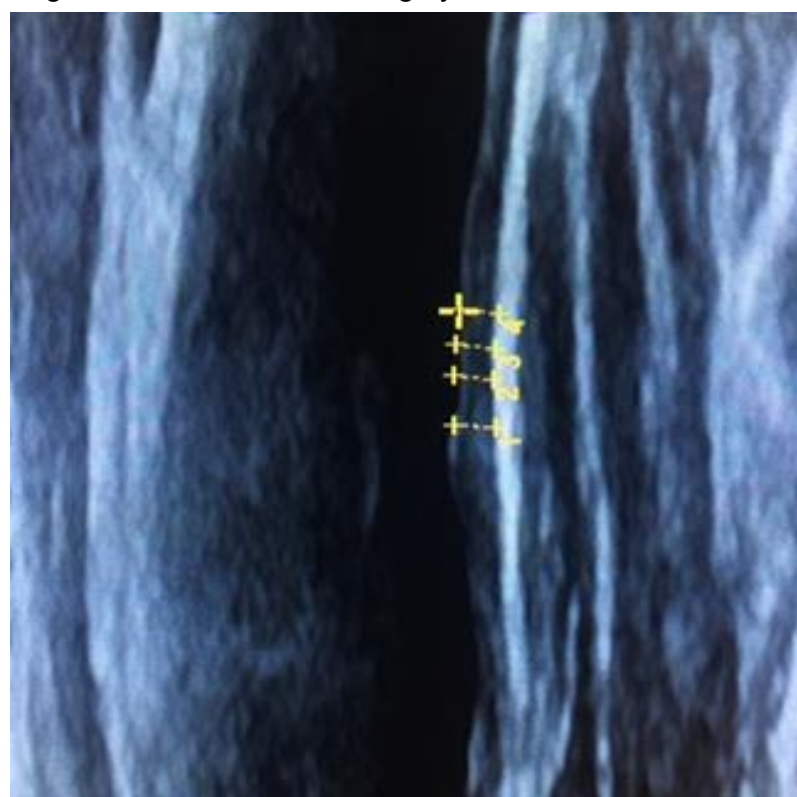

Şekil-2. Karotis intima-media ölçümü.
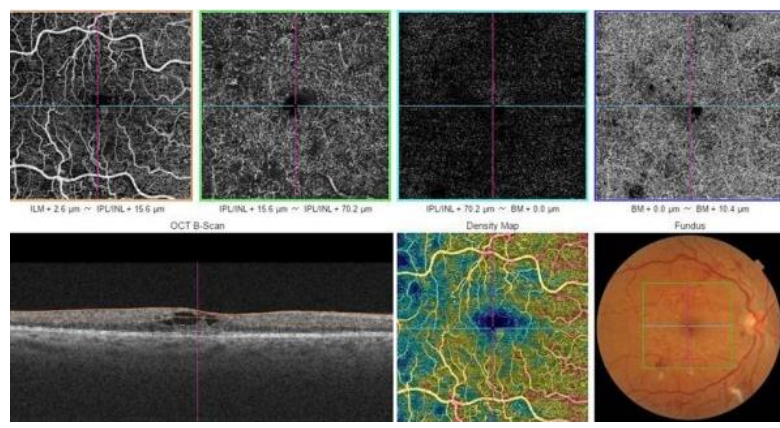

Şekil-3. OKTA'da foveal avasküler zonda genişleme ve çentiklenme.

\section{Kaynaklar}

1. The DECODE Study Group on behalf of the European Diabetes Epidemiyology Group: Glucose tolerance and cardiovascular mortality, comparison of fasting and 2-hour diagnostic criteria. Arch Intern Med 2001;161(3):397-404.

2. Ahluwalia N, Drouet L, Ruidavets JB, et al. Metabolic syndrome is associated with markers of subclinical atherosclerosis in a French population-based sample. Atherosclerosis 2006;186(2):345-53

3. Ahn SG, Lim HS, Joe DY, et al. Relationship of epicardial adipose tissue by echocardiography to coronary artery disease. Heart 2008;94(3):e7.

4. Altın C, Sade LE, Gezmiş E, Yılmaz M, Özen N, Müderrisoğlu H. Assessment of epicardial adipose tissue and carotid/femoral intima media thickness in insulin resistance. J Cardiol 2016;67(10):961-9.

5. Lee J, Rosen R. Optical coherence tomography angiography in diabetes. Curr Diab Rep 2016;16(12):123.

6. de Barros Garcia JMB, Isaac DLC, Avila M. Diabetic retinopathy and OCT angiography: Clinical findings and future perspectives. Int J Retina Vitreous 2017;13(3):14.

7. Dimitrova G, Chihara E, Takahashi H, Amano H, Okazaki K. Author Response: Quantitative retinal optical coherence tomography angiography in patients with diabetes without diabetic retinopathy. Invest Ophthalmol \& Vis Sci 2017;58(3):1767.

8. American Diabetes Association. Diagnosis and classification of diabetes mellitus. Diabetes Care 2010;33(Suppl 1):62-9. 
9. Unwin N, Shaw J, Zimmet P, Alberti KG. Impaired glucose tolerance and impaired fasting glycemia: The current status on definition and intervention. Diabet Med 2002;19(9):708-23.

10. Simon A, Gariepy J, Chironi G, Megnien JL, Levenson J. Intima-media thickness: A new tool for diagnosis and treatment of cardiovascular risk. J Hypertens 2002;20(2):159-69.

11. Poredos P. Intima-media thickness: Indicator of cardiovascular risk and measure of the extent of atherosclerosis. Vasc Med 2004;9(1):46-54.

12. Lim TK, Lim E, Dwivedi G, Kooner J, Senior R. Normal value of carotid intima-media thickness: A surrogate marker of atherosclerosis: quantitative assessment by B-mode carotid ultrasound. J Am Soc Echocardiogr 2008;21(2):112-6.

13. Cardellini M, Marini MA, Frontoni $S$, et al. Carotid artery intima-media thickness is associated with insulin- mediated glucose disposal in nondiabetic normotensive offspring of type 2 diabetic patients. Am J Physiol Endocrinol Metab 2007;292(1):347-52.

14. O'Leary DH, Polak JF, Kronmal RA, Manolio TA, Burke GL, Wolfson SK Jr. Carotid-artery intima and media thickness as a risk factor for myocardial infarction and stroke in older adults. Cardiovascular Health Study Collaborative Research Group. N Engl $J$ Med 1999;340(1):14-22.

15. Mancia G, Fagard R, Narkiewicz K, et al. List of authors Task Force members: 2013 Practice guidelines for the management of arterial hypertension of the European Society of Hypertension (ESH) and the European Society of Cardiology (ESC): ESH/ESC Task Force for the Management of Arterial Hypertension. J Hypertens 2013;31(10):1925-38.

16. lacobellis G, Assael F, Ribaudo MC, et al. Epicardial fat from echocardiography: a new method for visceral adipose tissue prediction. Obes Res 2003;11(2):304-10.

17. Smith HL, Willius FA. Adiposity of the heart: A clinical study of one hundred and thirty six obese patients. Ann Intern Med 1933;52: 911-31.

18. Taguchi R, Takasu J, Itani $\mathrm{Y}$, et al. Pericardial fat accumulation in men as a risk factor form coronary artery disease. Atherosclerosis 2001;157(1):203-9.

19. lacobellis G, Ribaudo MC, Assael F, et al. Echocardiographic epicardial adipose tissue is related to anthropometric and clinical parameters of metabolic syndrome: A new indicator of cardiovascular risk. J Clin Endocrinol Metab 2003;88(11):5163-8.

20. lacobellis G, Leonetti F, Di Mario U. Images in cardiology: Massive epicardial adipose tissue indicating severe visceral obesity Clin Cardiol 2003;26(5):237.

21. Gastaldelli A, Basta G. Ectopic fat and cardiovascular disease: What is the link? Nutr Metab Cardiovasc Dis 2010;20(7):481-90

22. lacobellis G, Leonetti F. Epicardial adipose tissue and insulin resistance in obese subjects. J Clin Endocrinol Metab 2005;90(11):6300-2.

23. Sengul C, Cevik C, Ozveren O ve ark. Echocardiographic epicardial fat thickness is associated with carotid intima-media thickness in patients with metabolic syndrome. Echocardiography $2011 ; 28(8): 853-8$.

24. Ahn SG, Lim HS, Joe DY, et al. Relationship of epicardial adipose tissue by echocardiography to coronary artery disease. Heart 2008;94(3):e7.

25. Mazurek T, Zhang L, Zalewski A, et al. Human epicardial adipose tissue is a source of inflammatory mediators. Circulation 2003;108(20):2460-6.

26. Kessels K, Cramer MJ, Veldhuis B. Epicardial adipose tissue imaged by magnetic resonance imaging: An important risk marker of cardiovascular disease. Heart 2006;92(2):262.

27. lacobellis G. Imaging of visceral adipose tissue: An emerging diagnostic tool and therapeutic target. Curr Drug Targets Cardiovasc Hematol Dis 2005;5(4):345-53

28. Ishibazawa A, Nagaoka T, Takahashi A, et al. Optical coherence tomography angiography in diabetic retinopathy: A prospective pilot study. Am J Ophthalmol 2015;160(1):35-44.

29. Hwang TS, Jia Y, Gao SS, et al. Optical coherence tomography angiography features of diabetic retinopathy. Retina 2015;35(11):2371-6 